the final chapters, he discusses the great Earthand space-based telescopes of the twentieth century that revolutionized our understanding of the origin and fate of the cosmos, and he offers a peek into the near future at a new generation of super telescopes that will probe even further into space.

Throughout the text there are useful diagrams and illustrations that ably illustrate the various lens and mirror configurations that have been designed during the telescope's first 400 years. There are also detailed notes, a glossary of astronomical and optical terms, and a bibliography.

Inevitably, there are a few minor errors. For example, Ptolemy's Almagest, an astronomy manual, should be dated to the middle of the second century AD, not the first century AD.
Watson's book is a welcome addition to the literature on the history of the telescope, and can be recommended to any reader with an interest in the history of science and instrumental technology.

Robert H. van Gent is at the Institute for the History and Foundations of Science, Utrecht University, Utrecht NL-3508 TA, The Netherlands.

\title{
Marine undercurrents
}

\section{An installation by Ellen Gallagher builds on some little-known work by Sigmund Freud.}

\begin{abstract}
Colin Martin
The house in Hampstead, London, where Sigmund Freud lived during the last year of his life, after leaving Vienna in 1938, has been a museum since 1986. His youngest daughter Anna, who died in 1982, left the study and library exactly as Freud used them, crammed with his furniture, books and extensive collection of antiquities. The house has a palpable sense of intellectual continuity, which has inspired contemporary artists to engage with Freud's ideas and create work for display there. American artist Ellen Gallagher's current installation, Ichthyosaurus, cites early work by Freud that he rarely mentioned in his later years. Although best
\end{abstract} known as the founder of psychoanalysis, Freud also worked as a neurologist and anatomist between 1876 and 1896. He began his scientific career assisting the physiologist Ernst Wilhelm von Brücke in Vienna, studying the spinal nerve ganglia of a primitive fish, the lamprey (Petromyzon), to gain insight into the evolution of nervous systems.

Fifteen of Freud's drawings of Petromyzon from 1876 and 1877 (like the example shown on the right) are displayed for the first time, in conjunction with Gallagher's installation. Her interventions in his library and study are discreet, and their extent becomes apparent only after looking carefully into the cordoned-off rooms. Immediately obvious are two 16-mm films made in collaboration with Edgar Cleijne, Ichthyosaurus 2005, which are projected onto the walls. Although they initially appear to be family home movies, they are cinematic riffs on Gallagher's marine theme: one shows flailing

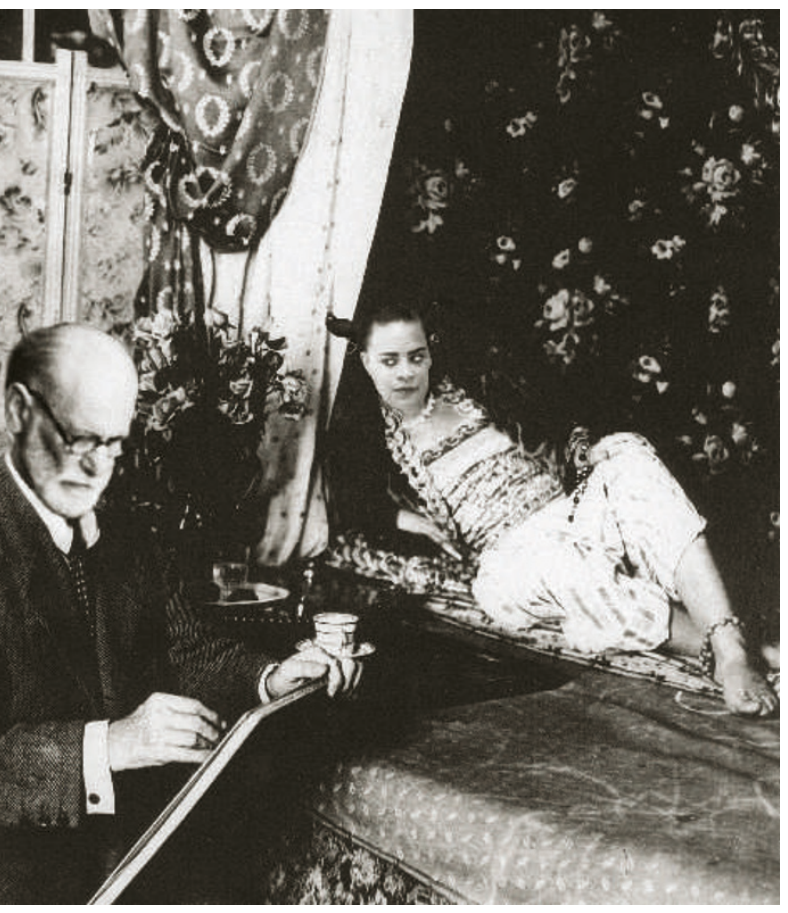

has hung three mixed-media works from her 'Watery Ecstatic' series, begun in 2001, on his walls. Fortunately, it is possible to view two further works located in the hall more closely and appreciate her skilful use of various techniques. These include intricately cut and coloured paper to form fish scales in Watery Ecstatic 2005 and cut layers of uncoloured paper to form fossil-like imprints of marine species in Watery Ecstatic (22 078 N, 159322 W) 2005.

Although her work is beautiful, it is unclear how Gallagher's appropriation of marine imagery provides more than a cursory nod towards Freud's early scientific work. His intention was simply to make

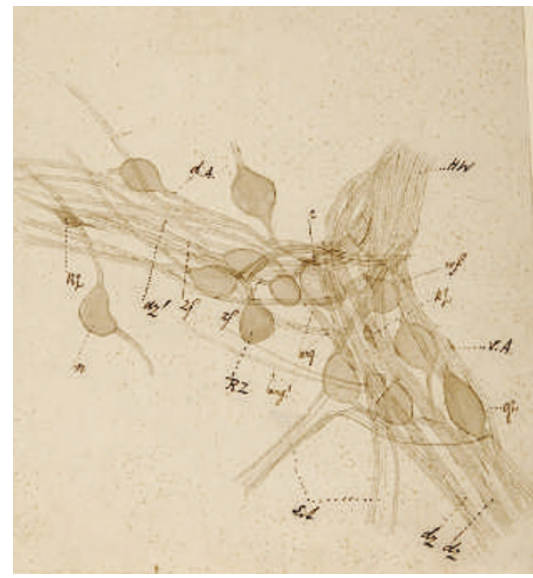

strands of seaweed, and the other spotlights various marine specimens that are difficult to discern from a distance.

Gallagher has also placed three glass specimen jars containing fanciful marine creatures among Freud's own objects, and drawings that presented cellular structure clearly, whereas she attempts to present multilayered personal and cultural meanings in her work.

Freud's influence appears more marked in Gallagher's two playful collages inspired by surrealism, the artistic movement that evolved from his psychoanalytical theories. In her photomontage Odalisque 2005 (shown here, above left), a seductively reclining Gallagher fails to divert Freud from his drawing board. In Abu Simbel 2005, she reworks a copy of the photogravure of an Egyptian temple that used to hang above Freud's couch in Vienna, adding a marinelike spacecraft complete with blue fur tentacles, which zaps rays at the colossal statues of Rameses II.

Ichthyosaurus can be seen at the Freud Museum (www.freud.org.uk) in London until 11 September.

Colin Martin is a London-based writer. 